${ }^{\circ}$ Entomologica Fennica. 19 June 1996

\title{
A new species of Coelinidea (Hymenoptera, Braconidae) from Myanmar
}

\author{
Ekaterina Gannota
}

\begin{abstract}
Gannota, E. 1995: A new species of Coelinidea (Hymenoptera, Braconidae) from Myanmar. — Entomol. Fennica 7:7-8.

Coelinidea peculiaris sp.n. (Hymenoptera, Braconidae, Alysiinae) is described from Kambaiti, Myanmar. Odd characteristics of radius and stigma of the fore wing readily separate the new species from all previously known representatives of the genus. This is also the first record of the genus from the Oriental Region.
\end{abstract}

Ekaterina Gannota, Zoological Museum, P.O. Box 17, FIN-00014 University of Helsinki, Finland

Received 25 October 1993, accepted 15 March 1995

During a visit to the Swedish Museum of Natural History, Stockholm, I checked collections of Alysiinae. Amongst a number of specimens collected by a Swedish expedition to Burma (now Myanmar) I found an interesting species described below.

\section{Coelinidea peculiaris sp.n.}

(Figs 1a-b)

Holotype o N.E. BURMA, Kambaiti, 2000 m, 11/6. 1934 Malaise" (known only by the holotype deposited in the Swedish Museum of Natural History, male unknown).

Body length $3.8 \mathrm{~mm}$. Wing length $3.2 \mathrm{~mm}$. Head, thorax, petiole and second tergite of abdomen dark brown; flagellum brown, scapus and pedicel yellow-brown; mandibles brown, palps yellow; fore and middle legs brownish-yellow as well as trochanters and apical parts of coxae of hind legs; bases of hind coxae and hind femora brown, hind tibiae and tarsi dark brown; abdomen, behind second tergite, yellowish-brown; stigma and wing veins yellow.

Head weakly transverse, 1.4 times as wide as long, not widened behind eyes in dorsal view; face 1.2 times as wide as high, shiny and smooth with fine punctures at setal bases, setae long, midridge pronounced; ocelli in equal-sided triangle; occiput smooth and shiny, covered with long hairs quite dense near bases of mandibles; mandibles typical for Coelinidea (3-toothed plus additional tooth present as a small knob-like expansion on dorsal margin of long narrow tooth 2 , teeth 1 and 3 small) (Fig. 1a); labial palps 4-segmented, segments quite short; antenna $42+2$-segmented, third flagellomere 2.4 times as long as wide, tenth flagellomere 2 times as long as wide, all flagellomeres densely pubescent.

Mesosoma about 2.2 times as long as high. Pronotum in dorsal view with deep median pit, its lateral sides rugosely sculptured and densely pubescent. Notauli short and smooth, almost invisible under dense long hairs, covering entire mesonotum; midpit long, reaching the middle of mesonotum, crenulate inside; mesopleura very smooth and shiny, bare, with long hairs only at the anterior margin and the lower posterior corner; sternauli anteriorly as a row of fine punctures, posteriorly as smooth line; subalar area and propodeum rugose, with very sparse long hairs; propodeum with trace of median longitudinal carina at the middle of anterior margin; hind coxa smooth, sparsely pubescent; hind femur about 4 times as long as wide. 


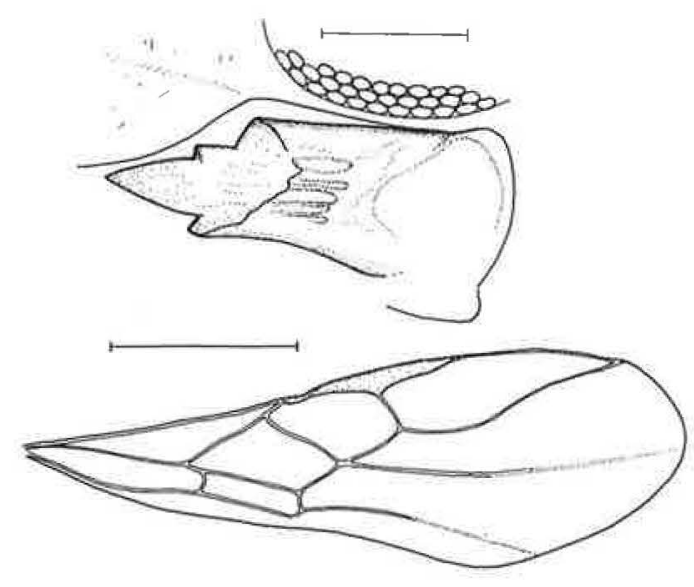

Fig. 1. Coelinidea peculiaris sp. $n$. a: left mandible; b: fore wing. - Scale bar a: $0.1 \mathrm{~mm}$; $b: 1 \mathrm{~mm}$.

First radial segment of fore wing about equal to width of stigma, arising proximal of mid-stigma, stigma 5 times as long as wide, remainder of radius unusually long and strongly sinuate; metacarpus 1.1 times as long as stigma; recurrent vein narrowly antefurcal; fore wing otherwise as in Fig. 1b.

Petiole of metasoma 4 times as long as apical width, rugulose; basal pits moderately shallow, dorsal carina short, angle between it and dorsolateral carina about 60; dorsope thus wide; second tergite 2 times as long as wide, parallelsided, flat, with the same sculpture as petiole; third tergite partially compressed, the following segments strongly compressed; only tip of ovipositor visible; all tergites densely setose, with setae more regularly arranged from the third tergite.

Notes: C. peculiaris is immediately recognized by the unusual radial vein, which is very long and strongly sinuate and arises from the middle of long stigma. Apart from this peculiar character, the new species fits the definition of Coelinidea as used at the generic or subgeneric rank in the latest works on the Coelinius-group (Griffiths 1964, Riegel 1982, Tobias 1986). Accordingly, the shape of radius cannot be used as a generic character, because it seems to be variable.

Alhough Wharton (in Wharton \& Austin 1991) included Coelinidea in Coelinius s.1., when he described a new species from Australia as Coelinius versicolor, in my opinion, Coelinius is a separate, still monotypic, genus (different type of mandibles and morphology of head). In the same article, mentioned above, Wharton made observation that Lepton Zetterstedt, 1838 has priority over Coelinidea Viereck, 1913 but Lepton has not been used in the primary literature since its original description. I therefore describe the new species as belonging to the genus Coelinidea. However, I completely agree with Dr. Wharton that the Coelinius-group needs thorough revision, taking into account also the genera Sarops Nixon, 1942 and Eucoelinidea Tobias, 1979.

\section{References}

Griffiths, G. C. D. 1964: The Alysiinae (Hym. Braconidae) parasites of the Agromyzidae (Diptera). I. General questions of taxonomy, biology and evolution. - Beitr. Entomol. 14: 823-914.

Riegel, G. T. 1982: The American species of Dacnusinae, excluding certain Dacnusini (Hymenoptera: Braconidae). - Novitates Arthropodae 3:1-184.

Tobias, V. I. 1986: [Identification of insects of European USSR. III. Hymenoptera 5]. - Opred. Faune SSSR 147:1-308 (in Russian).

Wharton R. A. \& Austin A. D. 1991: Revision of Australian Dacnusini (Hymenoptera: Braconidae: Alysiinae), parasitoids of cyclorrhaphous Diptera. - J. Australian Entomol. Soc. 30: 193-206. 